\title{
Regional variation in neonatal and post-neonatal mortality in Kenya
}

\author{
Lawrence D.E. Ikamari, PhD \\ Population Studies and Research Institute, University of Nairobi \\ P.O. Box 30197-00100, Nairobi, Kenya \\ Fax \# 25402245566 \\ likamari@uonbi.ac.ke
}

\begin{abstract}
This paper seeks to establish the effect of region of residence on neonatal and post-neonatal mortality in Kenya, using the 2003 Kenya Demographic and Health Survey data. The results show significant regional variation in neonatal and post-neonatal mortality. Both neonatal and post-neonatal mortality were also found to vary significantly according to household wealth status, household water supply, and toilet facility, maternal age at birth, preceding birth interval; antenatal visits and type of place of delivery. It was only postneonatal mortality that also varied significantly according to maternal education.
\end{abstract}

The study recommends that concerted efforts be made to reduce high neonatal and post-neonatal mortality in the high mortality areas. These could entail strengthening existing family planning, child survival and HIV/ AIDS programmes alongside improving households' access to piped water supply and household hygiene practices.

Key words: Region, variation, neonatal, post-neonatal mortality, Kenya

\section{Abstrait}

Cet article cherche aétablir l'effet de la région de résidence sur la mortalité néonatale et postnatale au Kenya, basé sur les données de l'enquêtede 2003 sur la santé et les faits démographiques du Kenya. Les résultats montrent des variations régionales significatives par rapport à la mortalité néonatale et postnatale. On a constaté que tous les deux, la mortalité néonatale et postnatale varient selon la fortune des ménages, l'approvisionnement de l'eau et des toilettes, l'âge maternel au moment de naissance, l'intervalle entre les accouchements successifs, les visites prénatales ainsi que le lieu d'accouchement. La mortalité postnatale seule, variait fortement selon le niveau d'education maternelle.

L'étude recommendé qu'on ait des actions concertées afin de réduire le taux élevéde mortalité néonatale et postnatale. Ces efforts peuvent comporter le renforcement des programmes existants de planification familiale, de la survie infantile et de VIH/SIDA. Ceux-ci peuvent occasionner l'amélioration de la canalisation d'eau aux foyers et des pratiques d'hygiènes des ménages.

Mots clés : Région, variation, mortalité néonatale, postnatale, le Kenya.

\section{Introduction}

Child health and survival is a concern of families, communities and nations throughout the world. Infant and child mortality are considered the most sensitive indicators of a nation's health status and level of socio-economic development (Hope, 1992). Historically, infant and child mortality in more developed countries steadily declined since the turn of the 20th century and, currently, has been reduced to almost minimal levels. In contrast, although infant and child mortality has declined in the past three decades in most developing countries, the pace of change and the magnitude of improvement vary considerably from country to country and within the same country (Gwatkin, 1980, Gwatkin et al. 2007).

In demographic literature several social and biological determinants of infant and child mortality are well documented (Hobcraft, et al. 1984, Hobcraft, 1993; Caldwell, 1979; Ikamari, 1996, 2002, Mustafa and Odimegwu, 2008 Chowdhury et al. 2010). For instance, the influence of parental education on infant and child health and mortality has proved to be universally significant (Bicego and Boerma, 1991; 1993; Caldwell, et al. 1990). Father's and mother's education and their work status each have independent effects on child survival in developing countries (Caldwell, et al. 1983; Chowdhury et al. 2010). As in many other developing countries, large regional variation in infant and child mortality in Kenya has been found in most of the studies (lkamari, 1996, 2000, CBS et al. 2004). Similarly, biological factors such as maternal factors like the age of the mother at childbirth, birth order and birth interval have been found to have significant effects on infant and child mortal- 
ity (Ikamari, 1996, 2000). The risk of dying during early childhood is also affected by the survival status of the preceding sibling (Zenger, 1993; Ikamari, 2000). Moreover, some studies found correlation in deaths of infants within a family (lkamari, 2000; Curtis, et al. 1993; Das Gupta, 1990, Zenger, 1993).

Early childhood mortality in Kenya, as in many developing countries, is still high. In 2003, infant mortality was estimated at 77 deaths per thousand live births; 43 per cent of these deaths occurred during the neonatal period and 57 percent in the postneonatal period (CBS et al., 2004). Research on social determinants of neonatal and post-neonatal mortality is scant. Most studies have focused on infant mortality and child mortality. This has resulted in little understanding of the social determinants of neonatal and post-neonatal mortality in the country. For example, it is not known whether there are significant regional variations in neonatal and post-neonatal mortality in the country. If there are, do they remain statistically significant in the presence of other social and biological determinants of early childhood mortality? This study seeks to contribute to filling this gap in knowledge. The study will primarily focus on establishing the effect of region of residence on neonatal and post-neonatal mortality since many recent studies indicate substantial regional variation in many demographic phenomena in Kenya (CBS et al. 2004; Ikamari, 1996, Brockerhoff and Hewett, 1998).

\section{Literature review and theoretical framework}

In Kenya there are significant socio-economic regional variations and the regions have been impacted differentially by modernisation. There are eight provinces in Kenya, namely Nairobi, Central, Coast, Eastern, Rift Valley, Nyanza, Western and North Eastern. Generally for historical and political reasons, Nairobi, Central and some parts of the Rift Valley province are more economically developed than Coast, Eastern, Nyanza, Western, North Eastern province, and some parts of dry parts of the Rift Valley province. The latter group of provinces are located at the periphery of the capital city Nairobi, which is the seat of government. These regional socio-economic disparities are bound to affect child survival. Children born to mothers residing in more developed provinces are expected to have lower neonatal and post-neonatal mortality risks than their counterparts in less developed provinces.

Furthermore, there are discernible regional cultural variations in Kenya, as one or two ethnic groups predominantly inhabit each of the eight regions. For example, Central Province is predomi- nantly inhabited by the Kikuyu, Coast Province by the Mijekenda, Nyanza by the Luo and Kisii, Western Province by the Luhya, Eastern by Kamba, Embu and Meru, Rift Valley by the Kalenjin, North Eastern by the Somali and Boran, while Nairobi Province is metropolitan.

Each ethnic group has its own socio-cultural ideologies about childbearing, health seeking behaviour, feeding practices and child health. These ideologies are composed of norms, beliefs and values as well as practices. It is likely that each cultural group may stress certain aspects in their reproductive institutions. These group norms, ideals and beliefs have been used to explain ethnic variation in many demographic outcomes (Addai and Trovato, 1999; Arnaldo, 2004). We also expect significant variation in the neonatal and post-neonatal mortality across the regions of Kenya due to the cultural differences.

Kenya is located in East Africa and lies between longitudes $34^{\circ}$ and $42^{\circ}$ East and between latitudes of $4^{\circ} 2 I^{\prime}$ 'North and $4^{\circ} 28^{\prime}$ 'South. It is a medium-sized country with a land area of 528,647 square kilometres. It has common borders with Ethiopia and Sudan to the north, Somalia to the north east, Tanzania to the south, Uganda and Lake Victoria to the west. To the east, it has a coastline on the Indian Ocean. Administratively, Kenya is divided into eight regions known as provinces. These are: Nairobi, Central, Coast, Eastern, Rift Valley, Nyanza, Western and North Eastern.

Kenya may be divided into five major ecological/ agricultural zones. These zones are: the Lake Victoria Basin, the Central rift and associated highlands, the northern, north-eastern, southern semi-arid and arid areas, the eastern plateau, and the coastal zone (Ominde, 1984: I-5). The Lake Victoria Basin covers the Western and Nyanza provinces, and the western parts of the Rift Valley province. The elevation of this zone varies from I, I 28 metres around Lake Victoria to over I,524 metres along the Rift Valley. In this zone the annual rainfall varies from 1,016 to 1778 $\mathrm{mm}$. Temperatures vary between $10^{\circ}$ and $32^{\circ} \mathrm{Cel}-$ sius. This zone contains some of the most fertile lands in the country and a variety of food and cash crops can be grown, with low risk of crop failure. However, some areas surrounding the Lake are infested with tsetse fly and mosquitoes. Hence malaria is a common disease in this zone (MPND and UNICEF, 1992: 58).

The Central Rift and associated highlands zone covers the Central province, the eastern parts of the Rift Valley province and the western parts of the Eastern province. Altitude in this zone ranges from I,829 metres at the floor of the Rift Valley to 5, I82 metres at Mt. Kenya. The annual rainfall is between $762 \mathrm{~mm}$ and I,524 $\mathrm{mm}$, the temperatures average 
$17^{\circ}$ Celsius and the risk of crop failure is low. The former "White Highlands"l fall within the zone. This zone contains rich volcanic soil and has a very high agricultural potential. Due to its high altitude, this zone is generally free from tsetse fly and mosquito infestation; hence malaria is not as common as in the Lake Basin or in the Coastal zone (Ominde, 1988).

The northern, north-eastern and southern semiarid and arid zone cover the entire North/Eastern province, north and southern parts of the Rift Valley province, and north-western parts of the Coast province. This is the largest geographical zone, and is characterised by a vast amount of agriculturally unproductive land. This zone covers about 83 per cent of Kenya's land. The annual rainfall is generally less than $508 \mathrm{~mm}$ and the average temperature is $26^{\circ}$ Celsius. This is a pastoral area and supports dry bush vegetation.

The Eastern plateau zone is located in the south-eastern section of Kenya and extends from the eastern boundaries of the highland areas to within $66 \mathrm{~km}$ from the coast. This zone has been, historically, highly susceptible to drought. Many areas suffer from tsetse fly infestation, and the area is noted for its grassland plains, sporadic wooded grasslands and semi-desert areas (Ominde, 1988: 4). Rainfall in the zone is scanty and unreliable, averaging between 508 and $762 \mathrm{~mm}$ annually. Agriculturally, this zone has low potential and the risk of crop failure is very high (MPND and UNICEF, 1992: 7).

The Coastal zone extends inland from the coastline on the Indian Ocean for about $64 \mathrm{~km}$ and is characterised by swampland and coral features. The Zone reaches an elevation of 137 metres. Agriculturally, this zone has both medium and low potential. Some areas receive an average of $900 \mathrm{~mm}$ of rainfall annually, and temperatures for the zone average $27^{\circ}$ Celsius. This zone also suffers from tsetse fly and mosquito infestation (Ominde, 1988: 4; MPND and UNICEF; 1992: 58). We expect regional variation in neonatal and post-neonatal mortality in Kenya partly due to the above ecological differences.

We have included in this study some other factors indicated in the demographic literature to be closely associated with infant and child mortality in Kenya and elsewhere. These other variables include maternal education, maternal factors such as age, preceding birth interval, health seeking behaviour and household environmental conditions (Bhan, 1994, Bicego and Boerman, 1991, 1993; Merrick, 1985; Lauren et al. 2009; Chowdhury et al. 2010). We adopt and use the Mosley and Chen Framework (1984) as a guide. This framework represents a complex theoretical paradigm expressed in a simple way, which helps to identify particular determinants of child health and survival. This framework is based on the proposition that socio-economic factors such as region of residence do not directly affect the outcome variable but rather must operate through proximate variables to affect child survival (1984). In this case, the proximate variables include maternal factors such as maternal age at birth and preceding birth intervals; health seeking behaviour (antenatal visits, place of delivery) and household environmental conditions.

In line with the Chen and Mosley framework, the socio-economic factors are: maternal education, household possessions and place of residence. Maternal factors are maternal age at the time of birth, preceding birth interval; and environmental factors are source of drinking water and toilet facilities. In addition, birth weight is included as a nutritional factor and antenatal care and place of delivery are included as proxies for health seeking behaviour.

We hypothesize that region of residence and each of the other factors discussed above have a significant effect on neonatal and post neonatal mortality. However, we shall examine their effect in the presence of the control variables. If the effects of region of residence are substantially reduced in their presence, then it will be established that the region of residence affects neonatal and post-neonatal mortality through these variables. If its effect is not reduced or is increased instead, it will be established that the region of residence affected neonatal or and post-neonatal mortality independently of these control variables.

\section{Data and methods}

As indicated earlier, the data for this study is drawn from the 2003 Kenya Demographic and Health Survey (KDHS). The KDHS was conducted to collect data on fertility, marriage, sexual activity, fertility preferences, family planning, maternity history, maternal and child health, information about HIV/ AIDS and other sexually transmitted diseases, information on malaria and use of mosquito nets and domestic violence. The survey was carried out as part of the world-wide DHS program. The surveys covered a national representative sample of women aged 15-49 years. This study focuses on 5949 live births born within five years preceding the survey i.e. between 1998 and 2003 to the sample women.

Mortality data was collected in the maternity history section of the women's questionnaire. The sections had questions about the aggregate childbearing experience of each respondent (woman). For each of the births, more detailed information was col-

I. These were highland areas that were settled by white settlers during the colonial rule in Kenya. 
lected on the sex, the month and year of birth, survivorship status, and current age if the child was alive, and age at death if the child had died.

The quality of mortality data depends upon the completeness with which births and deaths were reported and recorded, displacement of birth dates and misreporting of the age at death. Assessment done on the quality of the data indicates no major misreporting or underreporting of the birth and deaths (CBS et al. 2004). The high quality of the $2003 \mathrm{KDHS}$ data could be due mainly to the effectiveness of the various measures that were put in place during the preparation, the collection and processing of the data. The descriptions and discussions of the measures are found in the $2003 \mathrm{KDHS}$ Kenya Country Report (CBS et al. 2004).

It is worthwhile to mention that educational attainment variable was measured as at the time of the survey. As discussed extensively in the demographic literature, there is a problem in principle with the use of educational attainment as a determinant of the child survival if education is attained later than the initiation child bearing. However, in the Kenyan context education is actually attained before the onset of child bearing, at least for most women. It is assumed that the socioeconomic and environmental conditions of the families remained more or less the same during the five years period before the survey. Therefore, the household conditions when the children were born assumed to be the same as when the data were collected. In addition, the analysis is restricted to the births that occurred during five years preceding the 2003 Kenya Demographic and Health Survey.

In Kenya, a large proportion of births occur at home and it is difficult to obtain the exact birth weights of these babies. In the $2003 \mathrm{KDHS}$, respondents who had a live birth in the preceding five years were asked to indicate whether in their assessment the baby was very large, large, medium, small or very small at the time of the birth. This is clearly far from a birth weight, but it would be meaningful if the mother herself evaluates her baby as being very large or very small than average. Low birth weight poses greater threat to children born in conditions prevailing in slums or villages of developing countries than to children born in societies with adequate medical services and satisfactory physical and cultural environment (Kimm, 1979). Babies born very big are abnormal babies and their risk of mortality during neonatal period is higher than the normal size born babies (Rees et al. 1999).

Regular antenatal care is needed to help detect and manage pregnancy related complications and educate women about danger signs, potential complications, and where to seek help. Antenatal care beginning early in the first trimester of pregnancy and continuing on a regular basis is important to the health of both mother and infant. Early antenatal care provides an opportunity to offer preventive care that will benefit the infant as well as the mother such as counselling on hygiene, breastfeeding, nutrition, family planning, tetanus toxoid immunization and iron and foliate supplementation. Antenatal care also benefits treatment of existing diseases that may be aggravated by pregnancy. Antenatal care helps prevent complications during pregnancy and labour. Also, there is a negative association between timing of antenatal care and low birth-weight. If a woman's pregnancy goes to term, she may typically have anywhere from 10 to 14 antenatal visits. In the 2003 $\mathrm{KDHS}$, if the respondent reported antenatal care was taken, then the question regarding the number of visits were also asked.

With regard to place of delivery, for each live birth that a woman may have had during the three years preceding the $2003 \mathrm{KDHS}$, she was asked to indicate where the delivery took place. It is a fact that deliveries at medical institutions are safer, both for mother and child. Hence, higher child survival rates are expected for these deliveries. The assumption is that mothers who deliver in hospitals will be aware of better child health care practices. In the Kenyan context, these include the importance of breastfeeding, hygiene, nutrition and immunization. Moreover, hospitals are assumed to maintain safe delivery environments, and newborns may have fewer chances of contamination. Hence, children born in health facilities should be better off than children born at home or at any place other than a health facility.

The dependent variable used is neonatal and post-neonatal survival time. It is measured as the duration starting from the infant birth to death. For the purpose of this study, two observation periods have been identified and are modelled separately in analysis: from birth to less than 30 days or zero completed months (neonatal period); and the period between $I$ and 12 months (post-neonatal). Live births that survived beyond these observational periods are considered to be right censored. Data analyses are performed using Cox regression (Kleinbaum and Klein, 2005). The use of Cox regression in studying demographic phenomena such as child survival is fairly common in the literature (Bracher and Santow, 1998; Choe et al. 2004; Gyimah, 2003, Arnaldo, 2004, Ikamari, 2005).

Model fitting was done stepwise. Five models were fitted for each of the two periods, that is neonatal and post neonatal mortality. Model I contains only the region of residence as an explanatory variable. This is due to the importance of the region of 
residence as portrayed in the literature. Model 2 contains four variables; region of residence, education, type of place of residence and household wealth index. It therefore assessed the relative effect of region of residence in the presence of the controls for socio-economic conditions. Model 3 includes the variables in Model 2 plus source of drinking water and type of toilet facility variables. It assesses the relative effect of region of residence in the presence of the controls for both socio-economic and environmental conditions of the household. Model 4 contains all the variables included in Model 3 plus maternal age, birth weight of the child and preceding birth interval. Model 5 is the full model that includes all the covariates. It includes the variables in Model 4 plus pre natal visits and place of delivery. In summary the models described above are as follows:

Model I: Region of residence

Model 2: Model I + maternal education + type of place of residence + wealth index

Model 3: Model $2+$ Source of drinking water + toilet facility

Model 4: Model $3+$ maternal age at birth + birth weight + preceding birth interval

Model 5: Model $4+$ Antenatal visits + place of delivery.

We present the results as odds ratios, which represent the relative likelihood of a child with specific characteristics dying during a specified period of infancy in comparison to a child in the reference group. The odds ratio of the reference group is one (I.00). If the odds ratio of a given category is greater than 1.00 , it indicates increased the likelihood of having a death compared to the reference group; when the odds ratio is less than one (I.00), it indicates a lower risk of having a death compared to the reference group. In the analysis a variable will be reported as having a significant effect if its effect on the risk a child death is statistically significant at least at the 5 per cent level of significance.

Before the analysis whose results are reported here was carried out, a test of the violation of the proportionality assumption was carried out on the data using the selected study variables. The analysis performed, using the log-log plots and the scaled Schoenfeld residuals, did not show any evidence of violation of the assumption by any of the study variables.

\section{Results}

Table I shows the results of the hazard model analysis in relation to neonatal mortality. The results are shown in the form of hazard risk ratios and the significance level. In Model I, it is evident that children living in Nyanza $(O R=1.62, p<0.00)$ and North Eastern $(\mathrm{OR}=1.44, \mathrm{p}<0.05)$ have significantly higher neonatal mortality risk compared to the children living in Nairobi province (Reference). However, children living in Central province have a lower neonatal mortality risk $(O R=0.71, p<0.05)$ compared to children living in Nairobi Province. Children living in all other provinces have more or less the same neonatal mortality risk as those living in Nairobi province.

When education, the type of place of residence and household wealth index variables are included in the model (See Model 2), neonatal mortality risk difference between children living in Central province and those living in Nairobi increased $(O R=0.66, p$ $<0.05$ ) indicating that the difference in the levels of education, the type of place of residence and wealth index mask the large difference in the neonatal mortality risk between children living in Nairobi and those living in Central province. The neonatal mortality risk among children living in Nyanza province is slightly reduced $(O R=1.45, p<0.00)$ while the mortality risk difference among children living in North Eastern province disappears. With regard to education, children born to women with at least secondary education had a significantly lower neonatal mortality risk $(O R=0.59, p<0.00)$ compared to children whose mothers had no education. The neonatal mortality risk among children whose mothers had primary education was more or less the same as that for children whose mothers have no education. Both the type of place of residence and household wealth index has no significant net effect on neonatal mortality.

In Model 3, when the source of drinking water and type of toilet facility variables are included, children living in households without piped water supply (Well, OR= I.26, $\mathrm{p}<0.05$ ) have significantly higher neonatal mortality risk compared to children living in households with piped water supply. As expected, children living in households with plush toilet facility have significantly lower neonatal mortality risk $(O R=0.78, p<0.05)$ compared to children living in households that have no toilet facility or have a pit toilet. Including these two variables in the model has the effect of lowering the neonatal mortality risk among children living in Central, Nyanza and Rift Valley provinces compared to the children living in $\mathrm{Nai}-$ robi province. These results suggest that the observed difference in the neonatal mortality between each of these provinces and Nairobi province is partly due to the differences in access to piped water supply and household environmental conditions measured in terms of type of household toilet facility.

In Model 4, it is clear that maternal age at birth, 
baby weight at birth and the preceding birth interval each have a significant net effect on neonatal mortality. Maternal age of at least 35 years is associated with an elevated neonatal mortality risk. However, unexpectedly, the neonatal mortality risk is significantly lower among babies whose birth weight was considered by their mothers as being small $(O R=$ $0.7 \mathrm{I}, \mathrm{p}<0.05$ ). Similarly, first born children and children with a preceding birth interval of at least 18 months had significantly lower neonatal mortality risk compared to children whose preceding birth interval was less than 18 months.

In Model 5, it was apparent that utilisation of antenatal care and the type of place of delivery each had a significant net effect on neonatal mortality. Children whose mothers had received modern antenatal care (clinic visits) had lower mortality risk com- pared to the children whose mothers did not make any antenatal clinic visits. The results indicate that the neonatal mortality risks declined with the number of clinic visits made. For instance, making at least 4 clinic visits lowered the neonatal mortality risk by $5 \mathrm{I}$ per cent. Surprisingly, children delivered in a public health facility had a higher neonatal mortality risk $(O R=I .45, p<0.01)$ compared to children delivered at home. The neonatal mortality risks were more or less the same among children delivered in a private health facility and those born at home. Including these two variables in the model has the effect of increasing the effects of region of residence, household wealth index, source of drinking water and maternal age at birth on neonatal mortality risk.

Table I Hazard rate ratios obtained from Proportional Hazard Model for Predicting Neonatal Mortality, KDHS 2003

\begin{tabular}{|c|c|c|c|c|c|}
\hline Covariates & Model I & Model 2 & Model 3 & Model 4 & Model 5 \\
\hline \multicolumn{6}{|l|}{ Region of Residence } \\
\hline Nairobi (RC) & 1.00 & 1.00 & 1.00 & 1.00 & 1.00 \\
\hline Central & $0.7 I^{*}$ & $0.66 *$ & $0.56 * *$ & $0.55^{* * *}$ & $0.51 * *$ \\
\hline Coast & 1.02 & 0.86 & $0.76^{*}$ & 0.79 & 0.84 \\
\hline Eastern & 0.84 & $0.72 *$ & $0.58 * *$ & $0.6 I^{* *}$ & $0.52 * *$ \\
\hline Nyanza & $1.62 * *$ & $1.45 * *$ & 1.16 & 1.16 & 1.5 I** \\
\hline Rift Valley & 0.93 & 0.81 & $0.65 * *$ & $0.59 * *$ & $0.7 I^{*}$ \\
\hline Western & 1.18 & 1.04 & 0.81 & 0.77* & 0.78 \\
\hline North Eastern & I.44* & 1.11 & 0.88 & 0.97 & 0.86 \\
\hline \multicolumn{6}{|l|}{ Level of education } \\
\hline No education (RC) & & 1.00 & 1.00 & 1.00 & 1.00 \\
\hline Primary & & 0.94 & 0.93 & 1.13 & 1.10 \\
\hline At least secondary & & $0.59 * *$ & $0.6 I^{*} *$ & 0.79 & 0.96 \\
\hline \multicolumn{6}{|c|}{ Type of place of residence } \\
\hline Urban(RC) & & 1.00 & 1.00 & 1.00 & 1.00 \\
\hline Rural & & 0.96 & 0.90 & 0.88 & 0.79 \\
\hline \multicolumn{6}{|c|}{ Household wealth Index } \\
\hline Poor (RC) & & 1.00 & 1.00 & 1.00 & 1.00 \\
\hline Middle & & 1.11 & 1.13 & 1.15 & $0.47 * *$ \\
\hline Rich & & 0.96 & 1.00 & 1.02 & $0.68 * *$ \\
\hline \multicolumn{6}{|c|}{ Source of drinking water } \\
\hline Piped (RC) & & & 1.00 & 1.00 & 1.00 \\
\hline Well & & & $1.26 *$ & $1.26 *$ & $\mathrm{I} .34 *$ \\
\hline Other Sources & & & $1.29 *$ & $1.30 *$ & $1.34 *$ \\
\hline \multicolumn{6}{|l|}{ Toilet facility } \\
\hline No toilet (RC) & & & 1.00 & 1.00 & 1.00 \\
\hline Pit toilet & & & 1.02 & 1.04 & 0.89 \\
\hline Flush toilet & & & $0.78 * *$ & $0.68 * *$ & $0.51 * *$ \\
\hline \multicolumn{6}{|c|}{ Maternal age at birth } \\
\hline 20 years $(\mathrm{RC})$ & & & & 1.00 & 1.00 \\
\hline $20-34$ years & & & & 1.05 & $1.42 *$ \\
\hline
\end{tabular}




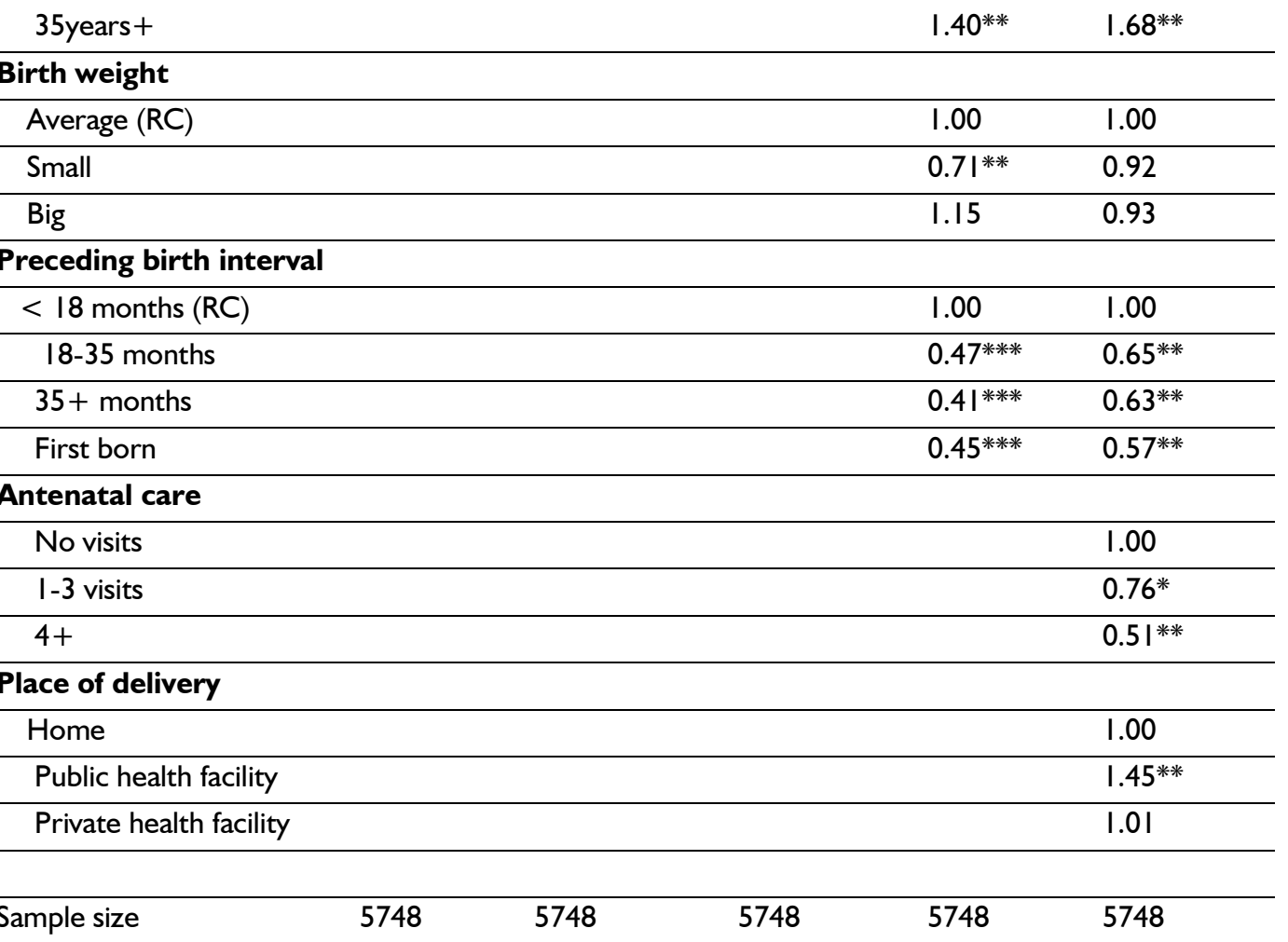

\section{Post-neonatal mortality}

Table 2 presents the results of the hazard models fitted on post neonatal mortality. In model I, it is evident that children living in Nyanza province $(O R=$ 2.77, $\mathrm{p}<0.00)$, Western $(\mathrm{OR}=1.94, \mathrm{p}<0.00)$ and North Eastern $(1.56, \mathrm{p}<0.00)$ had significantly higher post-neonatal mortality risk compared those living in Nairobi. However, children living in Central, Coast, Eastern and Rift Valley provinces had significantly lower post-neonatal mortality risk.

When education, the type of place and household wealth variables are added into the model (Model 2), the post-neonatal mortality risk among children living in Central, Coast, Eastern and Rift Valley provinces increased compared to the children living in Nairobi province. The mortality risk among children living in Nyanza and those living in Western provinces was slightly reduced while the mortality risk difference of living in Eastern province disappears. With regard to education, children born to mothers with at least secondary education had a significantly lower post neonatal mortality risk compared to children whose mothers had no education $(O R=0.47, p<0.00)$. The mortality risk for children whose mothers had primary education was more or less the same as that of children whose mothers had no education. The type of place of residence had no significant net effect on post-neonatal mortality. Household wealth index had a significant effect on post-neonatal mortality. However, the mortality risk among the children whose mothers belonged to middle household index was significantly higher $(O R=1.37, \mathrm{p}<0.05)$.

In Model 3, when the source of drinking water supply and the type of toilet facility are included, mortality risk among children belonging to the households without piped water (Well, OR=1.20, $p$ $<0.05)$, other sources, $O R=1.36, p<0.05)$ is significantly higher compared to the mortality risk of children belonging to households with piped water. As expected, children belonging to households that have a flush toilet facility have significantly lower mortality risk $(O R=0.76, p<0.05)$. Including these variables in the model, has the effect of further lowering post-neonatal mortality risk among children living in Central, Coast, Eastern, Rift Valley, Nyanza and Western provinces compared to the children living in Nairobi province. These results suggest that the observed differences in post-neonatal mortality between each of these provinces and Nairobi province is partly due to differences in access to piped water supply and having a toilet facility.

In Model 4, when maternal age at birth, baby weight at birth and the preceding birth interval variables are added, it is evident that only the preceding birth interval has a significant effect on post neonatal mortality. First born children and children with preceding birth intervals of at least 18 months have significantly lower post-neonatal mortality risks.

In Model 5, utilisation of preventive health care services like antenatal care has significant effect on post-neonatal mortality. Children whose mothers had at least four antenatal clinic visits have significantly lower mortality $(O R=0.59, p<0.00)$. Simi- 
larly the type of place of delivery has a significant effect. Again, as in the case of neonatal mortality, children who were delivered at a public health facility have higher post-neonatal mortality $(\mathrm{OR}=1.52$, $\mathrm{p}<0.00)$ compared to children delivered at home. Children delivered in private health facilities also have an elevated mortality risk but it is not significant at the 5 per cent $(O R=1.17, p<0.10)$. These results are not unique. Similar results have been found in Pakistan (Mohamed; 2003). Including antenatal care and the type of place of delivery in the model has the effect of increasing the effects of region of residence, household wealth index, source of drinking water supply and maternal age at birth on post-neonatal mortality. However, it lowered the effect of the preceding birth interval on post-neonatal mortality.

Table 2 Hazard rate ratios obtained from Proportional Hazard Model for Predicting Post neonatal Mortality, KDHS 2003

\begin{tabular}{|c|c|c|c|c|c|}
\hline Covariates & Model I & Model 2 & Model 3 & Model 4 & Model 5 \\
\hline \multicolumn{6}{|l|}{ Region of residence } \\
\hline Nairobi (RC) & 1.00 & 1.00 & 1.00 & 1.00 & 1.00 \\
\hline Central & $0.58 * *$ & $0.47 * * *$ & $0.43 * *$ & $0.44 * *$ & $0.27 * *$ \\
\hline Coast & $0.62 *$ & $0.45 * * *$ & $0.42 * *$ & $0.39 * *$ & $0.27 * *$ \\
\hline Eastern & 0.69* & $0.50 * *$ & $0.46 * *$ & $0.46 * *$ & $0.30 * *$ \\
\hline Nyanza & 2.77 **** & $2.25 * * *$ & $2.00 * *$ & I.87** & $1.43 * *$ \\
\hline Rift Valley & $0.62 *$ & $0.48 * * *$ & $0.42 * *$ & $0.39 * *$ & $0.25 * *$ \\
\hline Western & I.94** & $1.5 I^{* * *}$ & I.38* & $1.24 *$ & $0.67 *$ \\
\hline North Eastern & I.56** & 1.01 & 0.88 & 0.86 & $0.57^{*}$ \\
\hline \multicolumn{6}{|l|}{ Level of education } \\
\hline No education (RC) & & 1.00 & 1.00 & 1.00 & 1.00 \\
\hline Primary & & 0.91 & 0.93 & 1.07 & 1.15 \\
\hline At least secondary & & $0.42 * * *$ & $0.43 * * *$ & $0.5 I^{*} * *$ & $0.60 *$ \\
\hline \multicolumn{6}{|c|}{ Type of place of residence } \\
\hline Urban(RC) & & 1.00 & 1.00 & 1.00 & 1.00 \\
\hline Rural & & 0.95 & 0.87 & 0.87 & 0.89 \\
\hline \multicolumn{6}{|c|}{ Household wealth Index } \\
\hline Poor (RC) & & 1.00 & 1.00 & 1.00 & 1.00 \\
\hline Middle & & $1.37 *$ & $1.45 * *$ & $1.49 * *$ & $0.35 * *$ \\
\hline Rich & & 0.93 & 1.06 & 1.06 & $0.48 * *$ \\
\hline \multicolumn{6}{|c|}{ Source of drinking water } \\
\hline Piped (RC) & & & 1.00 & 1.00 & 1.00 \\
\hline Well & & & $1.20 *$ & 1.08 & $1.65 * *$ \\
\hline Other Sources & & & $1.36 *$ & $1.36 * *$ & $1.52 * *$ \\
\hline \multicolumn{6}{|l|}{ Toilet facility } \\
\hline No toilet (RC) & & & 1.00 & 1.00 & 1.00 \\
\hline Pit toilet & & & 0.87 & 0.83 & $1.86 * *$ \\
\hline Flush toilet & & & $0.78^{*}$ & 0.82 & $1.56 * *$ \\
\hline \multicolumn{6}{|l|}{ Maternal age at birth } \\
\hline 20 years $(\mathrm{RC})$ & & & & 1.00 & 1.00 \\
\hline 20-34 years & & & & 0.83 & $1.33^{*} *$ \\
\hline $35 y e a r s+$ & & & & 0.94 & $1.58 * *$ \\
\hline \multicolumn{6}{|l|}{ Birth weight } \\
\hline Average (RC) & & & & 1.00 & 1.00 \\
\hline Small & & & & 0.85 & 0.85 \\
\hline Big & & & & 0.99 & 0.89 \\
\hline \multicolumn{6}{|c|}{ Preceding birth interval } \\
\hline$<18$ months $(\mathrm{RC})$ & & & & 1.00 & 1.00 \\
\hline
\end{tabular}




\begin{tabular}{lll} 
I8-35 months & $0.59^{* *}$ & 0.93 \\
\hline $35+$ months & $0.52^{* * *}$ & $0.8 \mathrm{I}$ \\
\hline First born & $0.34^{* * *}$ & $0.47^{* *}$ \\
\hline Antenatal care & & \\
\hline No visits & 1.00 \\
\hline $\mathrm{I}-3$ visits & $0.65^{* *}$ \\
\hline $4+$ & $0.59^{* *}$ \\
\hline Place of delivery & & \\
\hline Home & & 1.00 \\
\hline Public health facility & & $1.52^{* *}$ \\
\hline Private health facility & & 1.17 \\
\hline Sample size & 5325 & \\
\hline & 5325 & 5325
\end{tabular}

\section{Discussion}

In both bivariate and multivariate results, significant regional variations in neonatal and post-neonatal mortality are evident. The risk of neonatal and postneonatal mortality remained persistently higher in Nyanza province compared to Nairobi province in most of the multivariate models. These results clearly show that region of residence is an important determinant of neonatal and post-neonatal mortality in Kenya. Similar results have been found in some other studies (Brockerhoff and Hewett, 1998; Ikamari, 2000, Otieno and Omollo, 2004; Omariba et al. 2008; Mustafa and Odimegwu, 2008). These results could be due to differences in socio-economic and ecological environmental conditions. HIV/ Aids could also be a contributory factor; HIV/AIDs prevalence is higher in Nyanza province than in Nairobi province (CBS et al. 2004)

Education of the mother had insignificant net effects on neonatal mortality but a significant net effect on post-neonatal mortality. As expected, children born to mothers with at least secondary education had a significantly lower post neonatal mortality risk (Model 5). This result is consistent with results found in many developing countries as indicated earlier. Type of place of residence does not have significant net effects on both neonatal and post-neonatal mortality. Household wealth index also had significant net effects on both neonatal and post-neonatal mortality. Generally, children belonging to wealthy households had a lower neonatal and post-neonatal mortality risk (Model 5).

As expected, both the source of household drinking water and toilet facility had net significant effects on both neonatal and post-neonatal mortality. Children belonging to households without a piped water supply had significant higher risk of neonatal and post-neonatal mortality. Similarly, children belonging to households without a toilet facility experienced higher neonatal and post-neonatal mor- tality risk compared to the children from households with a toilet facility.

Multivariate results obtained show that the risk of neonatal and post-neonatal mortality appeared to increase with maternal age at birth. For instance, in the case of neonatal mortality, odds of dying among children born to women aged 35 years was 1.68 times higher than those for the children born to women aged under 20 years. The corresponding odds for the post-neonatal mortality were I.58. These multivariate results do not depict the $U$ shape that often characterises the association between infant mortality and maternal age at birth in much of the demographic literature. However, the bivariate results (not presented here) showed the typical $U$ shaped association.

Birth weight did not have a significant net effect on neonatal mortality. Neither did it have a significant net effect on post-neonatal mortality. However, in the bivariate analyses, underweight (small) children were shown to have elevated neonatal and post-neonatal mortality risks. Preceding birth intervals had strong and significant net effects on neonatal mortality but weak net effects on post-neonatal mortality. In the case of neonatal mortality, the odds of dying decreased with the length of the preceding birth interval. As expected, first born children had a significantly lower net neonatal mortality risk compared to children with a preceding birth interval. This could be due to the advantages that first born children often enjoy, at least during their first year of life. For instance, they have the monopoly of parental attention since they are no other siblings to compete with them for parental, especially maternal, attention and household resources (Ikamari, 2000). However, during the post-neonatal period, the preceding birth interval does not have a significant net effect on the risk of mortality. However, as shown in Model 5 , it is only first born children that had significantly lower neonatal and post-neonatal mortality 
risk compared to children with preceding birth intervals of under eighteen months.

Antenatal visits had strong and significant net effects on mortality both during the neonatal and post-neonatal periods. As expected, children whose mothers had sought antenatal care during their pregnancy had much lower neonatal and post-neonatal mortality risk than children whose mothers had not sought antenatal care. The risks of dying decreased with the number of antenatal visits. These results are empirical evidence of the beneficial effects of antenatal care. These results are consistent with those found in Pakistan (Mahmood, 2002). Similarly, the type of place of delivery had significant net effects on both neonatal and post-neonatal mortality. However, children delivered at a public health facility had significantly higher neonatal and post-neonatal mortality risk compared to children delivered at home. Children delivered in private health facilities had more or less the same neonatal and post-neonatal mortality risk as children born at home. Similar results have been found in Pakistan (Mohamed; 2003).

\section{Conclusion}

The study recommends concerted efforts be made to reduce the high neonatal and post-neonatal mortality in the high mortality areas, particularly in Nyanza province. These could entail strengthening the capacity of existing child survival and HIV/AIDS and safe motherhood programmes and projects in these areas to improve quality of care and to widen access thereby increasing the uptake of the various child and maternal services.

The results obtained indicated children belonging to households without piped water supply and toilet facilities had elevated mortality risks. Improvement of access to piped water supply and household hygiene practices (including having clean and functioning toilets) will contribute to a reduction in neonatal and post neonatal mortality in the country. Therefore, this study recommends increased access to piped water supply in the country and for each household to have a clean and functioning toilet facility.

Efforts should also be made to increase birth intervals and to reduce child-bearing at early ages; also to encourage the uptake of antenatal care and have institutional delivery. In addition, efforts should be made to improve the quality of care in public health facilities.

\section{References}

Addai, I. and Trovato, L. 1999. "Structural assimilation and ethnic fertility in Ghana". Journal of Comparative Family Studies 30(3):409-427.

Allison, P. D. 1995. Survival Analysis Using the SAS System: A Practical Guide, Cary, North Carolina: SAS Institute Inc.

Allison, P.D. 1984. Event History Analysis: Regression for Longitudinal Data. Sage.

Arnaldo,C. 2004. "Ethnicity and Marriage Patterns in Mozambique". African Population Studies 19(I): 143-164.

Bhanu, B.N. 1994. 'Úse of health Services in Hill villages in Central Nepal', Health Transition Review, 4(2): I5I-I66.

Bicego, George T., and J. Ties Boerma (1993) Maternal Education and Child Survival: A Comparative Study of Survey Data from 17 Countries. Social Science and Medicine 36:9, I207-I 227.

Boerma, J.T. and G.Bicego, 1992. 'Preceding birth interval and child survival: searching for pathways of influence', Studies in Family Planning 23(4): 243267.

Brockerhoff Martin and Hewett, P. 1998. Ethincity and Child Mortality in Sub Saharan Africa. Population Council Working Paper No. 107.

Caldwell, J. 1979. 'Éducation as a factor in mortality decline: an examination of Nigerian data', Population Studies 33(3): 395-4I 2.

Caldwell, J. 1989. 'Routes to low mortality in poor countries'In J. Caldwell and G.M. Santow (eds). Selected Readings in the Cultural, Social and Behavioural Determinants of Health Series I, Health Transition Centre, The Australian National University: Canbera: pp I-46.

Central Bureau of Statistics (CBS) [Kenya], Ministry of Health, and ORC Macro. 2004. Kenya

Demographic and Health Survey, 2003. Calverton, Maryland: CBS, $\mathrm{MOH}$, and ORC Macro.

Chowdhury, Quamrul Hasan Chowdhury, Rafiqul Islam and Kamal Hossain, 2010 'Socio-economic determinants of neonatal, post neonatal, infant and child mortality', International Journal of Sociology and Anthropology Vol. 2(6), pp. I I8- I25, June 2010

Curtis, S.L. Diamond lan and MacDonald, J.W. 1993. Birth interval and family effects on post-neonatal mortality in Brazil. Demography 30(I): 33-43.

Das Gipta, M. 1990. Death clustering, mother's education and determinants of child mortality in rural Punjab, India, In: What We Know About Health Transition: The Culutural, Social and Behavioural Determinants of Health. Health Transition Series 2(I): 44 I-46I

Esrey, S. A. , and J. P. Habicht (1986) Epidemiologic Evidence for Health Benefits from Improved Water and Sanitation in Developing Countries. 
Epidemiological Review 8, I I7-1 28.

Gwaktin, D. 1980. Indicators of change in developing countries child mortality trends: the end of an era?', Population and Development Review 6(4):6I5-644.

Gwatkin D.R, Rutstein S, Johnson K, Suliman E, Wagstaff A, Amouzou A, 2007. Socio-economic Differences in Health, Nutrition and Population within Developing Countries: an Overview. Washington,DC: World Bank.

Gyimah, S.O. 2003. Women's Educational Attainment and the Timing of Parenthood in Ghana: A Cohort Perspective. Discussion Paper No: 03-04. Department of Sociology, University of Western Ontario, Canada.

Hale, Lauren, Julie DaVanzo, Abdur Razzaque and Mizanur Rahman, 2009. Which factors explain the decline in infant nad child mortality in Matlab, Bangladesh? Journal of Population Research 26: 320. Dol 10.1007/s I 2546-008-9003-0.

Hobcraft, J.N, J.W. MacDonald and S.O.Rutsein, 1984. 'Socio-economic factors in infant and child mortality: a cross national comparison', Population Studies 36(2) 193-233.

Hobcraft, J.N. 1993. 'Women's education, child welfare and child survival : a review of evidence', Health Transition Review 3(2): I59-I75.

Hope, K.R. 1992. 'Child survival and health care among low income Africa American families in the United States', Health Transition Review 2(2): |5|-163.

Ikamari, L. 2005. The effect of education on the timing of marriage in Kenya, Demographic Research 12 (I): I-27.

Ikamari, L. D.E. 1996. Factors affecting child survival in Kenya. PhD Thesis. The Demography Program. The Research School of Social Sciences. The Australian National University. Canberra: Australia.

Kimm, Sue, and G. Gonoso (1979) Control of Protein-calorie Malnutrition. In J. Mayer and T. Johanna Dwyer (eds.) Food and Nutrition Policy in a Changing World. New York: Oxford University Press.

Mahmood, M. Arshad , 2002. Determinants of
Neonatal and Post-neonatal Mortality in Pakistan, The Pakistan Development Review 41: 723-744.

Merrick, T.W. 1985. The effect of piped water on early child mortality in urbab Brazil, Demography (22(I): I-23.

Ministry of Planning and National Development (MPND) and UNICEF, 1992. Children and Women in Kenya: A Situation Analysis, Ministry of Planning and National Development, Nairobi.

Mosley, H.W. and L.C. Chen, 1984. 'An analytical framework for the study of child survival in developing countries', Supplement to Population and Development Review, 10 25-45.

Mustafa, Hisham Elmahdi and Clifford Odimegwu, 2008. Socioeconomic determinants of infant mortality in Kenya: Analysis of KDHS 2003. Journal of Humanities and Social Sciences, Vol 2(2); 2008.

Omariba, Walter Rusugu, Fernando Rajulton and Roderic Beaujot, 2008. Correlated mortalirt of Siblings in Kenya: The Role of State Dependence, Demographic Research Vol 18 article II.

Ominde, S. H., 1984. 'Introduction: a Bird's Eye View of the Republic in the Modern World', in S. H. Ominde with Roushdi Henin and David F. Sly (eds), Population and Development in Kenya, Heinmann Educational Books, Nairobi: pp. I-5.

Ominde, S. H., 1988. 'Demography and vector- born diseases in Kenya', in S. H. OMINDE (ed.), Kenya's Population Growth and Development to the year 2000, Heinemann, Nairobi: pp. 108-I 19.

Otieno Fredrick, and Christopher Omolla 2004. Infant and Child mortality in Kenya Demographic and Health Survey, 2003, Central Bureau Central Bureau of Statistics (CBS) [Kenya], Ministry of Health, and ORC Macro. 2004. Kenya Demographic and Health Survey, 2003.Calverton, Maryland: CBS, $\mathrm{MOH}$, and ORC Macro.

Rees, Jane M., Lederman, Sally A. Kiely, and L. John ( 1999) Neonatal Mortality among High Birth Weight Infants Born to African American Adolescent Mothers. Pediatric Research 45: 4

Zenger, Elizabeth, 1993. Siblings' Neonatal mortality Risks and Birth Spacing in Bangladesh.

Demography Vol. 30(2): 477-488. 